\title{
Proceeding Paper \\ Investigation of Membrane Fouling in Vacuum Membrane Distillation (VMD) Using Blocking Filtration Laws ${ }^{\dagger}$
}

\author{
Wajeeha Bibi *, Muhammad Asif and Jawad Rabbi (D)
}

check for

updates

Citation: Bibi, W.; Asif, M.; Rabbi, J. Investigation of Membrane Fouling in Vacuum Membrane Distillation (VMD) Using Blocking Filtration Laws. Eng. Proc. 2021, 12, 82. https://doi.org/10.3390/ engproc2021012082

Academic Editor: Shahid Iqbal

Published: 12 January 2022

Publisher's Note: MDPI stays neutral with regard to jurisdictional claims in published maps and institutional affiliations.

Copyright: (C) 2022 by the authors. Licensee MDPI, Basel, Switzerland. This article is an open access article distributed under the terms and conditions of the Creative Commons Attribution (CC BY) license (https:// creativecommons.org/licenses/by/ $4.0 /)$.
Faculty of Mechanical Engineering, GIK Institute of Engineering Sciences and Technology, Topi 23460, Pakistan; masif@giki.edu.pk (M.A.); jawad.rabbi26@gmail.com (J.R.)

* Correspondence: wajeehamalikzaman@gmail.com

† Presented at the 1st International Conference on Energy, Power and Environment, Gujrat, Pakistan, 11-12 November 2021.

\begin{abstract}
VMD is one of the desalination technologies used for drinking water purification because of it higher permeate flux and lower energy consumption, and it uses low grade energy for operation. However, there are some critical problems related to VMD, one of which is membrane fouling. In the present study, the fouling phenomenon in VMD is investigated using constant pressure-blocking filtration laws. The results of constant pressure-blocking filtration law indicated that the permeate flux was initially unaffected by the cake layer, but with the passage of time as the pores began to constrict, a formation of a relatively thick cake layer was observed, which resulted in the decrease of permeate flux.
\end{abstract}

Keywords: blocking filtration laws; membrane fouling; membrane distillation; VMD

\section{Introduction}

VMD is one of the most effective desalination technologies. During the VMD process, membrane scaling and fouling happens, and a cake layer forms on the membrane-feed interface that causes a reduction in flux. The resistance to flow due to cake formation becomes dominant with the duration of the desalination process [1]. Yun et al. [2] studied membrane fouling for high-salinity $\mathrm{NaCl}$ solutions in direct contact membrane distillation and reported that permeate flux decreases as the concentration of salt increases. Bhausaheb et al. [3] researched on ground water and salt solution desalination using a vacuum membrane distillation unit and showed a $29 \%$ decrease in permeate flux over a time period of $75 \mathrm{~h}$ for ground water.

\section{Modeling Procedure}

The general form of constant pressure blocking filtration laws is represented as:

$$
\frac{d^{2} t}{d V^{2}}=k\left(\frac{d t}{d V}\right)^{n}
$$

where $t(\mathrm{sec})$ is the filtration time, $V\left(\mathrm{~m}^{3}\right)$ is the cumulative volume, $k$ is a coefficient of fouling and $n$ is the parameter depending on fouling trait. The blocking laws shown in Figure 1 , presented by Hermia [4], described the fouling process by four models: (i) standard model of pore blocking; (ii) intermediate model of pore blocking; (iii) complete pore blocking model; and (iv) cake filtration model of blocking. The four models are presented in Table 1. 
(a)

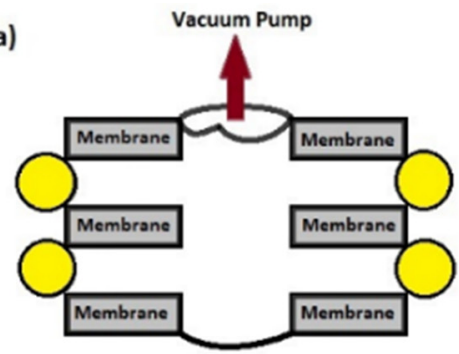

(b)

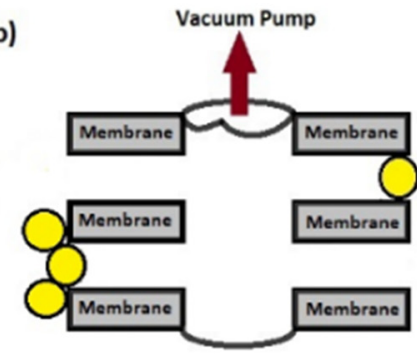

(c)

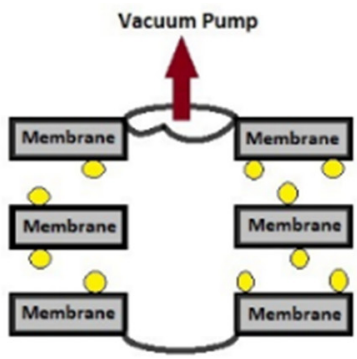

(d)

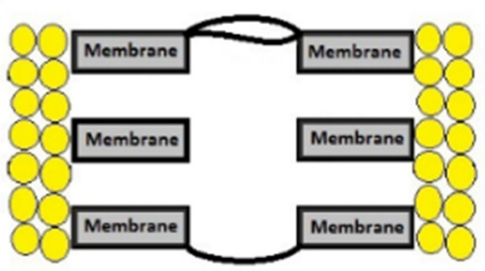

Figure 1. Membrane blocking by fouling. (a) Pore blocking (b) Intermediate blocking (c) Standard blocking (d) Cake layer.

Table 1. Blocking filtration models.

\begin{tabular}{cccc}
\hline & Linearized Form & $\mathbf{n}$ & Assumption \\
\hline $\begin{array}{c}\text { Standard } \\
\text { Blocking }\end{array}$ & $\frac{t}{V}=a t+b$ & 1.5 & $\begin{array}{c}\text { Deposition of particles smaller than } \\
\text { the pore size resulting in smaller pores }\end{array}$ \\
\hline $\begin{array}{c}\text { Intermediate } \\
\text { Blocking }\end{array}$ & $\frac{1}{J_{V}}=a t+b$ & 1 & Particles super-impose on each other. \\
\hline $\begin{array}{c}\text { Complete } \\
\text { Blocking }\end{array}$ & $-\ln \left(\frac{J_{V}}{J_{V, 0}}\right)=a t+b$ & 2 & $\begin{array}{c}\text { Membrane pores are completely } \\
\text { sealed off by the particles }\end{array}$ \\
\hline Cake filtration & $\frac{t}{V}=a V+b$ & 0 & $\begin{array}{c}\text { Particles deposit on membrane-feed } \\
\text { interface forming a cake layer }\end{array}$ \\
\hline
\end{tabular}

We used an approach similar to Yun [2] and applied the cake filtration model on the last region of the experiment which could be observed as linear. The cake filtration law parameters " $a$ " and " $b$ " are presented in Equations (2) and (3), respectively. These equations were applied to the results obtained from linearized cake filtration model to evaluate the specific cake resistance and clean membrane resistance.

$$
\begin{gathered}
a=\frac{\mu \cdot \alpha_{c} \cdot S}{2 \cdot A^{2} \cdot T M P} \\
b=\frac{\mu \cdot R_{m}}{T M P \cdot A}
\end{gathered}
$$

where $\mu$ is the viscosity of water in $\mathrm{Pa} \cdot s$ calculated from seawater correlations provided by Alsaadi [5], $\alpha_{c}$ is the specific cake resistance, $S$ is salinity of feed water, $A$ is area in $\mathrm{m}^{2}$, TMP is the trans-membrane pressure in $\mathrm{kPa}$, and $R_{m}$ is the clean membrane resistance in $\mathrm{m}^{-1}$.

\section{Results and Discussion}

\subsection{Experiment 1}

The experimental data were linearized. Figure 2a represents the standard blocking model applied on Experiment 1. The solid line represents the linear fit of the model, and the dashed lines are the prediction intervals of the linear fit. The residual sum of the squares value, which was calculated as 0.99 , represents a good fit for the points. The result shows that for the initial time up to $23 \mathrm{~h}$, standard blocking law fits the filtration data, resulting in a clear representation of membrane pore constriction. Figure $2 b$ represents the cake 
filtration model. The model fits with a residual sum of squares value (R-sq) of 0.9999 , as the last three points were observed to be linear.

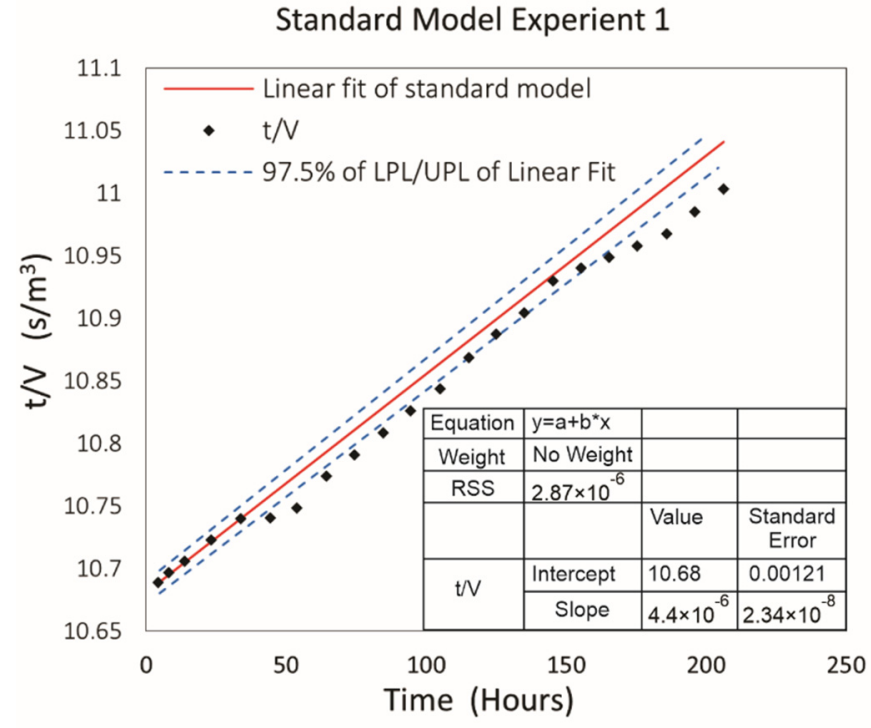

(a)

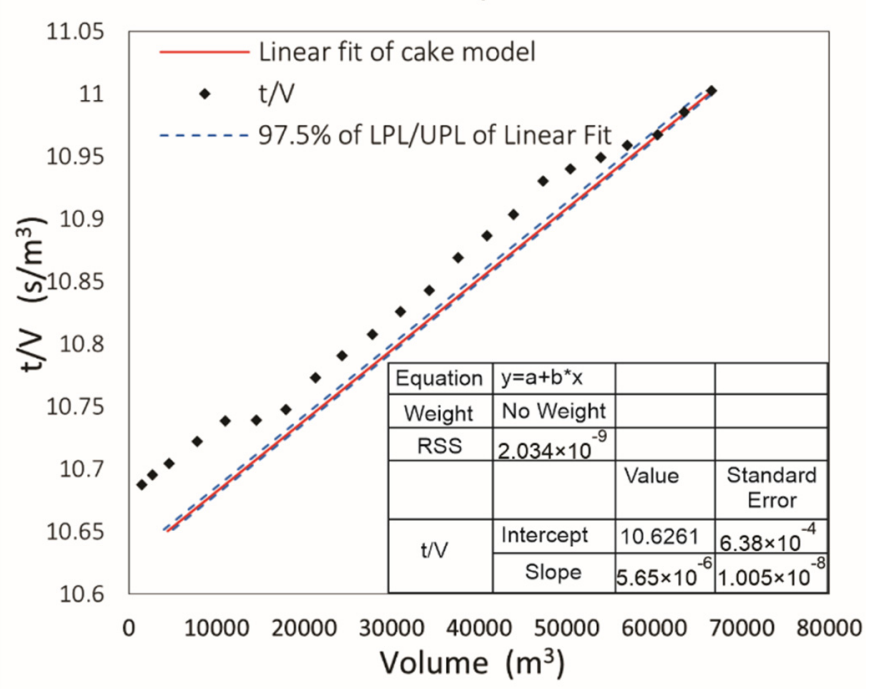

(b)

Figure 2. Application of blocking filtration laws on Experiment 1: (a) standard model, (b) cake filtration.

\subsection{Experiment 2}

Figure 3a represents the linear fit of standard model on the first part of Experiment 2. The initial three points were seen in a linear region; thus, the model was applied to this region. For Experiment 2, pore constriction is predicted linearly and continuously until $9.5 \mathrm{~h}$. This value is less than the value for Experiment 1, which is explained by the different input conditions and specifically the membrane pore size. Therefore, pore constriction would have a higher impact and cause a greater amount of fouling in a lesser duration. The cake filtration model is presented in Figure $3 \mathrm{~b}$. The model was applied on the last five points of the data as they were observed as linear and when the R-squared value was evaluated, it achieved 0.988 corresponding to a good fit for the data points.

Standard Model Experient 2

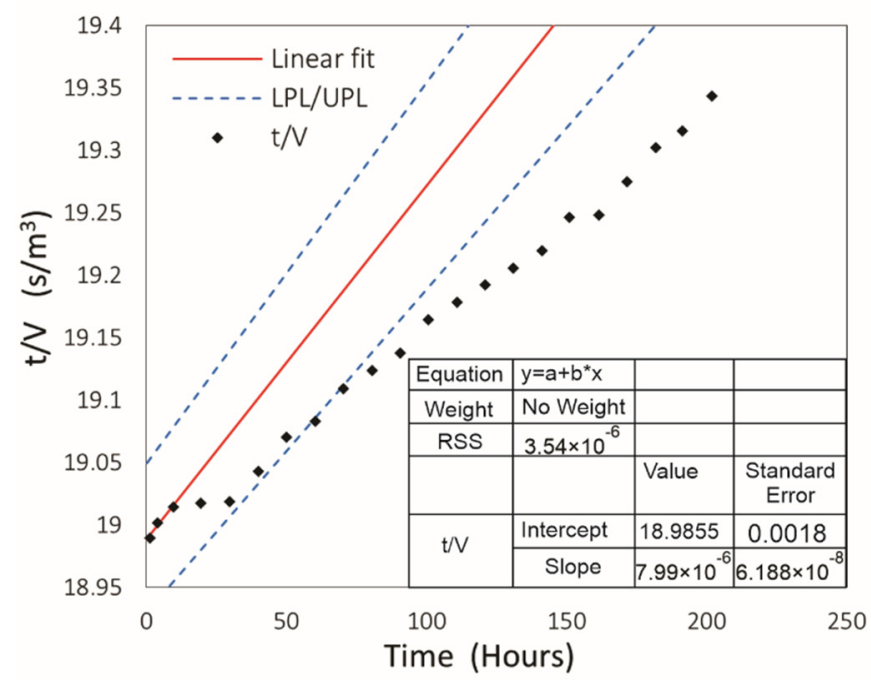

(a)

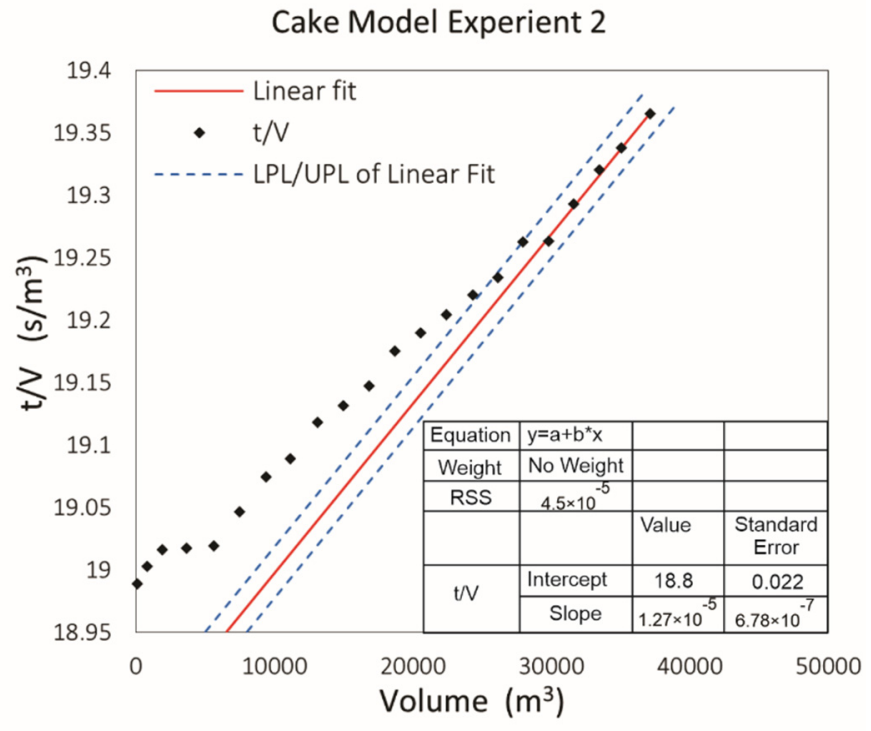

(b)

Figure 3. Application of blocking filtration laws on Experiment 2: (a) standard model, (b) cake filtration. 


\subsection{Experiment 3}

Experimental data from Bhausaheb [3] were utilized as Experiments 3 and 4. The results of Experiment 3 when linearized by $\mathrm{t} / \mathrm{V}$ vs. $\mathrm{t}$ were observed to have a zero gradient and moved horizontally until $70 \mathrm{~h}$. Due to this, the standard blocking model is inapplicable as we assume the pore blocking to be dominant during the initial time of the experiment. Figure 4a represents the cake filtration model that was applied to the last four points due to their linearity, and R-square was calculated to be 0.991 , presenting a good fit for the data points to the linearized cake model.

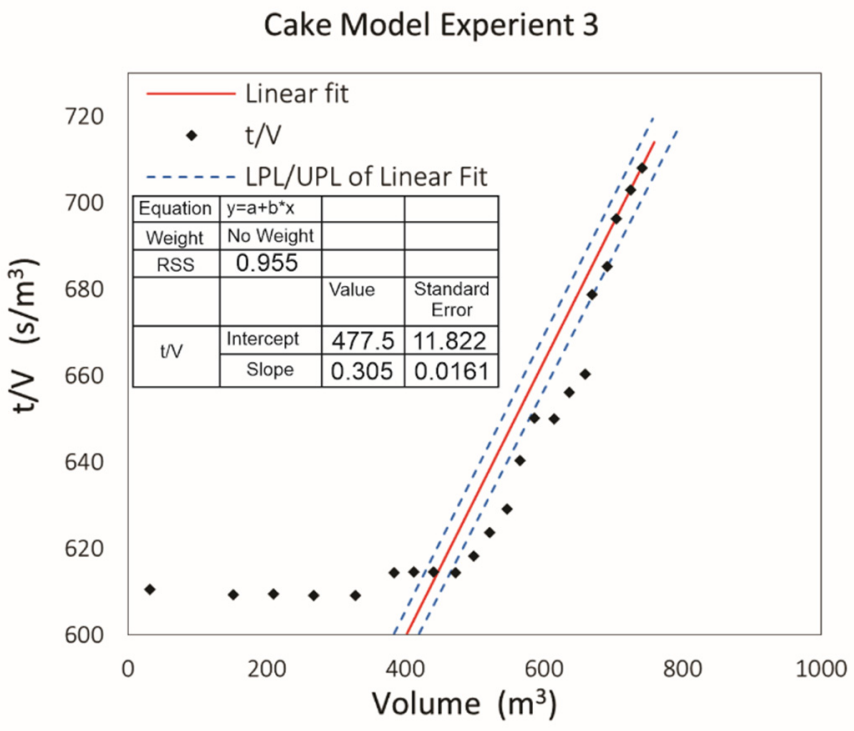

(a)

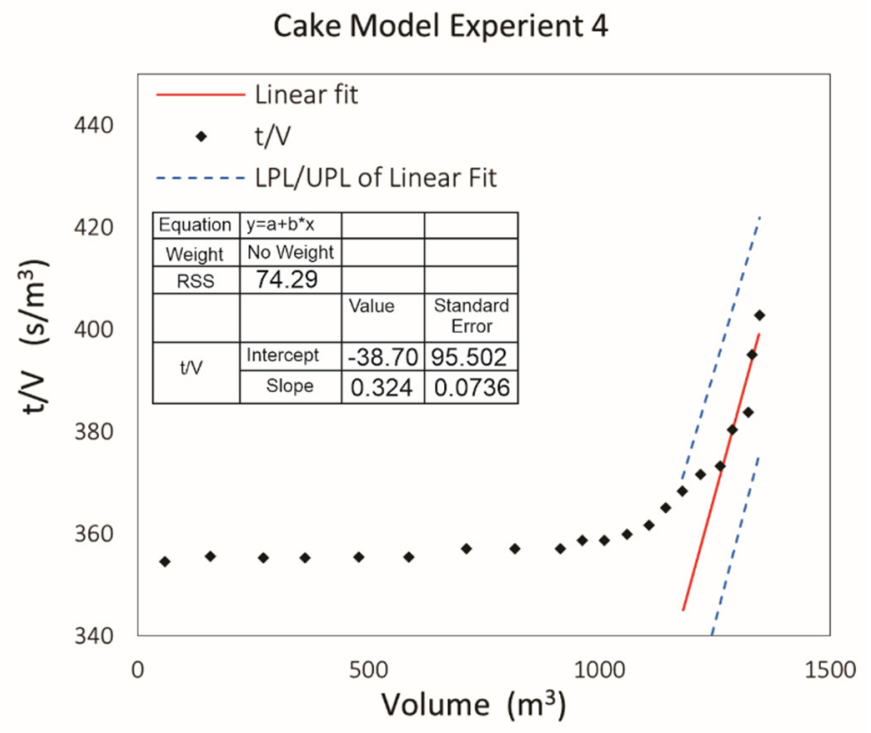

(b)

Figure 4. (a) Application of blocking filtration laws on Experiment 3: cake filtration; (b) application of blocking filtration laws on Experiment 4: cake filtration.

\subsection{Experiment 4}

Similarly, for Experiment 4, the standard blocking model could not be applied because the plot of $t / V$ vs. $t$ was horizontal and no slope existed. The cake model was applied on the last five points of the experiment and achieved an R-squared value of 0.822 , which is the lowest from all the four experiments, as illustrated in Figure $4 \mathrm{~b}$. $\alpha \mathrm{c}$ was calculated from Equation 12 as $12.4 \times 109 \mathrm{~kg} / \mathrm{m}$, which is the highest calculated of the four experiments. The intercept was negative for this experiment. Therefore, the clean membrane resistance could not be calculated.

\section{Conclusions}

The use of blocking filtration laws helped in predicting the fouling. Predicting fouling is a difficult task as these processes are usually simultaneous with their effects varying with time, such that when the filtration begins, a cake layer starts to form. This would vary based on the operating conditions, and simultaneously some feed particles could also block the pores or constrict them. Thus, at the start of the filtration process, the pore blocking phenomenon would be dominant along with pore constriction, but as time proceeds, a cake layer forms, which could contribute a dominating role in the reduction in flux, and the effects of pore constriction would become lesser as compared to the cake layer.

Author Contributions: Authors contribute equally to this paper. All authors have read and agreed to the published version of the manuscript.

Funding: This research received no external funding. 
Data Availability Statement: The data presented in this study are available on request from the corresponding author.

Conflicts of Interest: The authors declare no conflict of interest.

\section{References}

1. Wu, H.; Shen, F.; Wang, J.; Wan, Y. Membrane fouling in vacuum membrane distillation for ionic liquid recycling:Interaction energy analysis with the XDLVO approach. J. Memb. Sci. 2018, 550, 436-447. [CrossRef]

2. Yun, Y.; Ma, R.; Zhang, W.; Fane, A.G.; Li, J. Direct contact membrane distillation mechanism for high concentration NaCl solutions. Desalination 2006, 188, 251-262. [CrossRef]

3. Pangarkar, B.L.; Thorat, P.V.; Parjane, S.B.; Abhang, R.M. Performance evaluation of vacuum membrane distillation for desalination by using a flat sheet membrane. Desalin. Water Treat. 2010, 21, 328-334. [CrossRef]

4. Hermia, J. Constant Pressure Blocking Filtration Laws-Application To Power-law Non-newtonian Fluids. Inst. Chem. Engrs. Trans. 1982, 60, 183-187.

5. Alsaadi, A.S.; Francis, L.; Amy, G.L.; Ghaffour, N. Experimental and theoretical analyses of temperature polarization effect in vacuum membrane distillation. J. Memb. Sci. 2014, 471, 138-148. [CrossRef] 